OPEN ACCESS

Edited by:

Roxana Octavia Carare, University of Southampton, UK

Reviewed by:

Junming Wang,

University of Mississippi Medical Center, USA

Valentina Echeverria Moran, Bay Pines VA Medical Center, USA

${ }^{*}$ Correspondence: Chuang Guo, College of Life and Health Sciences, Northeastern University, No. 3-11, Wenhua Road, Heping District, Shenyang, 110819 Liaoning, China guoc@mail.neu.edu.cn

Received: 27 March 2015 Accepted: 15 May 2015

Published: 02 June 2015

Citation:

Guo C, Zhang Y-X, Wang T, Zhong $M-L$, Yang Z-H, Hao L-J, Chai $R$ and

Zhang S (2015) Intranasal

deferoxamine attenuates synapse loss via up-regulating the P38/HIF-1a pathway on the brain of APP/PS1

transgenic mice.

Front. Aging Neurosci. 7:104

doi: 10.3389/fnagi.2015.00104

\section{Intranasal deferoxamine attenuates synapse loss via up-regulating the P38/HIF-1 $\alpha$ pathway on the brain of APP/PS1 transgenic mice}

\author{
Chuang Guo ${ }^{1 *}$, Yu-Xin Zhang ${ }^{2}$, Tao Wang ${ }^{1}$, Man-Li Zhong ${ }^{1}$, Zhao-Hui Yang ${ }^{1}$, Li-Juan \\ $\mathrm{Hao}^{1}$, Rui Chai ${ }^{1}$ and Shuai Zhang ${ }^{1}$ \\ ${ }^{1}$ College of Life and Health Sciences, Northeastern University, Shenyang, China, ${ }^{2}$ Department of Anatomy, Hebei United \\ University, Tangshan, China
}

The widely recognized neuroprotective effect of iron chelators is contributed by their ability to prevent reactive oxygen species (ROS) generation via the Fenton reaction, which sequesters redox-active Fe. An additional neuroprotective mechanism of ironchelating compounds is to regulate the transcriptional activator hypoxia-inducible factor $1 \alpha(H \mathrm{~F}-1 \alpha)$. In the present study, we observed that intranasal administration of deferoxamine decreased beta-amyloid $(A \beta)$ deposition and rescued synapse loss in the brain of $A \beta$ precursor protein and presenilin-1 (APP/PS1) double transgenic mice. We found that deferoxamine (DFO) up-regulated HIF-1 $\alpha$ mRNA expression and its protein level, and further induced the proteins that are encoded from HIF-1-adaptive genes, including transferrin receptor (TFR), divalent metal transporter 1 (DMT1), and brain-derived neurotrophic factor (BDNF). The effects of DFO on the induction and stabilization of HIF-1 $\alpha$ were further confirmed in vitro. This was accompanied by a decrease of $\mathrm{Fe}$ in the $\mathrm{CA} 3$ region of the hippocampus. Western blotting studies revealed that DFO differentially enhanced the phosphorylation of mitogen-activated protein kinase (MAPK)/P38 kinase in vitro and in vivo. The results suggest that the DFO may upregulate several HIF-1-dependent neuroprotective-adaptive genes in $A D$ via activating P38/HIF-1 $\alpha$ pathway, which may serve as important therapeutic targets to the disease.

Keywords: Alzheimer's disease, deferoxamine, hypoxia inducible factor, synapse, iron, transgenic mouse

\section{Introduction}

Alzheimer's disease $(\mathrm{AD})$ is the most common and progressive neurodegenerative disease. There is no effective therapy for $\mathrm{AD}$. One of the characteristics of the disease is the presence of beta amyloid protein aggregates and cell and synapse loss. A large body of evidence suggests that the etiology of $\mathrm{AD}$ is multifactorial and results from interactions among genetic, environmental, and endogenous factors (Migliore and Coppedè, 2009).

\footnotetext{
Abbreviations: $A \beta$, amyloid- $\beta$; AD, Alzheimer's disease; APP, amyloid precursor protein; APPsw, amyloid precursor protein Swedish mutant; BACE1, $\beta$-Site APP cleaving enzyme 1; BDNF, brain-derived neurotrophic factor; DFO, deferoxamine; DMT1, divalent metal transporter 1; GAPDH, glyceraldehyde 3-phosphate dehydrogenase; GSK$3 \beta$, glycogen synthase kinase- $3 \beta$; HIF, hypoxia inducible factor; HRE, hypoxia-response element; HRP, horseradish peroxidase; IHC, immunohistochemistry; MAPK, mitogen-activated protein kinase; PS1, presenilin 1; TBS, Trisbuffered saline; TFR, transferrin receptor.
} 
Although most AD cases are sporadic without known genetic mutations, Fe overloading appears to play an important role in the cause and/or consequence of $\mathrm{AD}$ during the aging process. Chelation therapy has been suggested as a valuable therapeutic approach in neurological disorders (Bandyopadhyay et al., 2010).

Deferoxamine (DFO), a metal chelator commonly used for the treatment of $\mathrm{Fe}$ overload, has been shown to have neuroprotective effects in animal models of stroke (Hanson et al., 2009), Parkinson's disease (Haleagrahara et al., 2013), age-induced loss of memory (de Lima et al., 2008). However, adverse effects associated with systemic administration of DFO, including systemic metal ion loss after long-term clinical application and poor penetration through the blood-brain barrier (BBB), have limited its use in this regard (Cuajungco et al., 2000). Compared to the systemic delivery for a chronic disease such as AD, nasal drug delivery system has a good permeability and can be targeted to the central nervous system (Yue et al., 2007), reducing systemic exposure with possible side effects. We recently reported that intranasal administered DFO can alter beta-amyloid $(A \beta)$ precursor protein (APP) processing, thereby decreasing $\beta$-Site APP cleaving enzyme 1(BACE1) and presenilin-1 (PS1) protein expression and resulting in the inhibition of $A \beta$ deposition, neuritic plaque formation, and memory deficit in APP/PS1 transgenic mice (Guo et al., 2013a). Several molecular mechanisms of action may take part in the beneficial neurotherapeutic properties of DFO. One of the key mechanisms underlying neuroprotection via $\mathrm{Fe}$ chelators is their antioxidant ability. Chelators prevent Fe from redox cycling, thereby suppressing hydroxyl radical formation via the Fenton reaction (Zecca et al., 2004). Another important DFO-triggered neuroprotective mechanism in $\mathrm{AD}$ may result from the stabilization and transactivation of hypoxia-inducible factor-1alpha (HIF-1 $\alpha$ ) pathway (Epstein et al., 2001; Jaakkola et al., 2001; Lando et al., 2002), leading to transcriptional up-regulation of a cassette of protective genes (Zaman et al., 1999; Siddiq et al., 2005). However, whether the neuroprotective effect of intranasal administered $\mathrm{DFO}$ on $\mathrm{AD}$ transgenic mouse brain is related to the action of HIF- $1 \alpha$ signaling pathway has not been fully clarified.

HIF-1 was identified as a $\alpha / \beta$ heterodimer, that is involved in hypoxic adaptation by transcriptionally inducing the expression of HIF-1 $\alpha$ target genes (Wang et al., 1995; Semenza, 1998). Under hypoxia, HIF- $1 \alpha$ is stable in the cytoplasm and can dimerize with HIF-1 $\beta$ in the nucleus, and then mediate the adaptation of cells to hypoxia by regulating the expression of genes involved in erythropoiesis, angiogenesis, glucose transport, and glycolysis, as well as genes relevant to Fe metabolism such as transferrin and the transferrin receptor (TFR; Semenza, 1999; Lee and Andersen, 2006; Tacchini et al., 2008). Interestingly, oxygen and $\mathrm{Fe}$ are required for the inhibition of HIF-1 $\alpha$ activity (Ivan et al., 2001), thus Fe chelators can mimic hypoxia and induce HIF-1 $\alpha$ stabilization (Mecklenburgh et al., 2002). Over the last decade, many studies have shown that DFO, which also induces and stabilizes HIF-1 expression, protects cultured cells from $\mathrm{A} \beta$ toxicity (Schubert and Chevion, 1995; Schubert et al., 2009) and inhibits AD progression in patients (Crapper McLachlan et al., 1991). These studies provided the clues to the possible involvement of HIF-1 in neurodegenerative disorders, which is now becoming more widely accepted.

However, despite the body of data suggesting that HIF-1 may be a good therapeutic target, more evidence is needed to further clarify the involvement of the HIF-1 signaling system in the neuroprotection contributed by $\mathrm{Fe}$ chelators in neurodegeneration pathologies, especially in vivo. Thus, we hypothesize that the neuroprotection exerted by DFO is in part due to the elimination of the HIF-1 $\alpha$ blockade. Here, we examined the effectiveness of intranasal administration of DFO for up-regulating HIF- $1 \alpha$ levels and subsequently activating proteins that are encoded from HIF-1-adaptive genes in APP/PS1 mice and human neuroblastoma SH-SY5Y cells stably transfected with human APP bearing the Swedish mutation (APPsw). Additionally, we determined the possible signaling pathways involved in this process.

\section{Materials and Methods}

\section{Transgenic Mice and Treatments}

The male APP/PS1 double transgenic mice used in this study were originally obtained from Jackson Laboratory. All experimental procedures were approved by the Laboratory Animal Ethical Committee of Hebei United University.

Mice (aged 6 months) were randomly assigned to control $(n=8)$ or DFO $(n=8)$ groups. DFO (Sigma D9533, $200 \mathrm{mg} / \mathrm{kg}$ body weight, dissolved in saline) and vehicle were administered intranasally once every other day for 3 months. For intranasal administration, a 50- $\mu$ l microsyringe was used to administer four 6- $\mu 1$ nose drops (alternating nares with 2 min between drops; $24 \mu \mathrm{l}$ total; $5 \mathrm{mg}$ DFO) to each mouse as described in previous reports (Hanson et al., 2009). At the age of 9 months, the mice were decapitated. The brains were rapidly removed and dissected into separate hemispheres on an icecooled board. The hippocampus and cerebral cortex were dissected from the left hemisphere and stored at $-80^{\circ} \mathrm{C}$ for Western blot and reverse transcription (RT)-PCR analyses. The right hemisphere was immersion fixed in $4 \%$ paraformaldehyde in phosphate buffered saline at $4^{\circ} \mathrm{C}$ overnight and routine paraffin sections $(5 \mu \mathrm{m})$ were prepared for morphological analysis.

\section{Fe Histochemistry with Perl's Staining}

Fe staining was performed on serial sections to analyze the distribution of $\mathrm{Fe}$ in the brains of transgenic mice using 3, $3^{\prime}$ diaminobenzidine-tetrahydrochloride (DAB)-enhanced staining Perl's staining. Briefly, sections $(5 \mu \mathrm{m})$ were routinely dewaxed, rehydrated, and treated in $0.1 \mathrm{M}$ Tris-buffer saline (TBS, $\mathrm{pH}$ 7.4) containing $3 \%$ hydrogen peroxide $\left(\mathrm{H}_{2} \mathrm{O}_{2}\right)$ for 10 min to reduce endogenous peroxidase activity. The sections were then immersed in Perl's solution containing equal parts of freshly made, aqueous potassium ferrocyanide (2\%) and hydrochloric acid (2\%) for $30 \mathrm{~min}$. After rinsing, the sections were finally intensified with $0.025 \%$ DAB plus $0.0033 \% \mathrm{H}_{2} \mathrm{O}_{2}$ in TBS for $10 \mathrm{~min}$. The process was monitored under 
the microscope to avoid strong background staining, and the duration of staining was the same for each animal. After several washes with distilled water, the sections were dehydrated, covered with neutral balsam and examined with a light microscope equipped with a digital camera. All slides were digitized using the optical fractionator technique. The Fe-positive areas (number of pixels) from the brain cortex and hippocampus were manually assessed using Adobe Photoshop. The results were quantified with Image-Pro Plus 6.0 software.

\section{Immunohistochemistry}

Routine avidin-biotinylated complex (ABC) immunohistochemical staining was performed to analyze the distribution of HIF- $1 \alpha$ in the APP/PS1 transgenic mouse brain. Briefly, paraffin sections were dewaxed, rehydrated and treated in $0.1 \mathrm{M}$ TBS containing 3\% hydrogen peroxide for $10 \mathrm{~min}$ to reduce endogenous peroxidase activity. After washing with TBS, sections were boiled in citric acid buffer for $3 \mathrm{~min}$ in a microwave oven. The sections were then rinsed, treated with $5 \%$ bovine serum albumin for $30 \mathrm{~min}$, and subsequently incubated overnight with rabbit anti- HIF-1 $\alpha$ (1:200; Novus $\mathrm{NB} 100-479)$ at $4^{\circ} \mathrm{C}$. After rinsing, sections were incubated with biotinylated goat anti-rabbit IgG (1:200) for $1 \mathrm{~h}$, followed by streptavidin peroxidase incubation for $1 \mathrm{~h}$ at room temperature. After rinsing, the sections were stained with $0.025 \%$ DAB for $3 \mathrm{~min}$. The stained sections were dehydrated, cleared, covered with neutral balsam, and examined under a light microscope equipped with a digital camera. Control sections were treated with identical solutions but without primary antibody followed by all subsequent incubations as described above.

\section{Cell Culture, Drug Treatment}

The APPsw cells were maintained in Dulbecco's modified Eagle's medium and Ham's F-12 nutrient mixture supplemented with $10 \%$ heat-decomplemented fetal calf serum, $100 \mathrm{IU} / \mathrm{mL}$ penicillin, $100 \mu \mathrm{g} / \mathrm{mL}$ streptomycin and $200 \mu \mathrm{g} / \mathrm{mL}$ G418 at $37^{\circ} \mathrm{C}$ in humidified $5 \% \mathrm{CO}_{2}$ air. Serum-free medium was added for $2 \mathrm{~h}$ when cells reached nearly $70-80 \%$ confluence before drug treatments. Cells were treated with $\mathrm{FeSO}_{4}(100 \mu \mathrm{M})$ or SB203580 (10 $\mu \mathrm{M}$, a P38 MAPK inhibitor) for $2 \mathrm{~h}$ and then treated with DFO $(100 \mu \mathrm{M})$. To ensure that the potential effects of Fe and DFO on HIF-1 $\alpha$ protein expression were not due to treatment-induced cell death, the concentrations of Fe and DFO selected were based on previously described studies (Guo et al., 2013a). After $24 \mathrm{~h}$, the cells were collected for Western blot analysis.

\section{Western Blotting}

For Western blots, the APP/PS1 transgenic mouse brain tissues and culture cells were homogenized in ice-cold lysis buffer containing a mixture of protease inhibitors. After homogenates were centrifuged at $12,000 \mathrm{rpm}$ for $30 \mathrm{~min}$ at $4^{\circ} \mathrm{C}$, supernatants were collected and the total protein levels were measured using a UV 1700 PharmaSpec ultraviolet spectrophotometer. Equal amounts proteins were resolved in $10 \%$ sodium dodecyl sulfate polyacrylamide gels and blotted on polyvinylidene fluoride membranes (Millipore, CA, USA). After blocking in 5\% non-fat milk for $1 \mathrm{~h}$, the membranes were incubated sequentially overnight at $4^{\circ} \mathrm{C}$ with the following primary antibodies: rabbit antiAPP695 (1:4000, Chemicon), rabbit anti- DIVALENT METAL TRANSPORTER 1 (DMT1)-IRE (1:3000, Alpha diagnostic), rabbit anti- DMT1-noIRE (1:3000, Alpha diagnostic), rabbit anti- HIF-1 $\alpha$ (1:1000, Novus), rabbit anti-p-JNK (1:1000, Cell Signaling Tech), rabbit anti-JNK (1:1000, Cell Signaling Tech), rabbit anti-p-ERK (1:1000, Cell Signaling Tech), rabbit antiERK (1:1000, Cell Signaling Tech); rabbit anti-p-P38 (1:500, Santa Cruz), rabbit anti-P38 (1:500, Santa Cruz); rabbit antisynaptophysin (SYP; 1:1000; Sigma-Aldrich); mouse anti-TFR (1:1000, Invitrogen); mouse anti- brain-derived neurotrophic factor (BDNF; 1:500, Chemicon), and mouse anti-GAPDH (1:10000, Kang Chen, KC-5G5). After washing, the membranes were incubated with horseradish peroxidase (HRP)-labeled secondary antibodies (1:5000; Santa Cruz) for $1 \mathrm{~h}$. Blots were visualized using Super Signal West Pico Chemiluminescent Substrate (Pierce Biotechnology, Rockford, IL, USA) and Chem Doc XRS with Quantity One software (BioRad, USA). The band intensities were quantified using Image-pro Plus 6.0 analysis software.

\section{RT-PCR}

Total RNA was extracted from APP/PS1 transgenic mouse brain tissue samples using Trizol (Invitrogen). After quantification by UV-spectroscopy at $260 \mathrm{~nm}$, total RNA of each sample was first transcribed to cDNA using EasyScriptTM Two-Step RT-PCR SuperMix (TransGen Biotech, AE401). PCR amplification was performed with reagents from TransGen Biotech. The cDNA solution was amplified with sequences of the following primers: HIF-1 $\alpha$, forward: TGGTATTATTCAGCACGAC, reverse: GAGACATT GCCAGGTTTAT; glyceraldehyde 3-phosphate dehydrogenase (GAPDH), forward: ACGGATTTGGTCGTATTGGG, reverse: CGCTCCTGGAAGATGGTGAT. The PCR conditions were: HIF- $1 \alpha, 30$ cycles of $94^{\circ} \mathrm{C}$ for $45 \mathrm{~s}, 50^{\circ} \mathrm{C}$ for $45 \mathrm{~s}$ and $72^{\circ} \mathrm{C}$ for $45 \mathrm{~s}$; GAPDH, 30 cycles of $95^{\circ} \mathrm{C}$ for $45 \mathrm{~s}$, $58^{\circ} \mathrm{C}$ for $45 \mathrm{~s}$, and $72^{\circ} \mathrm{C}$ for $60 \mathrm{~s}$. The PCR products were normalized with reference to GAPDH mRNA. The results were quantified with ChemDoc XRS Quantity One software.

\section{Immunohistochemistry and Confocal Laser Scanning Microscopy}

Cultured cells were seeded to sections. After treatment, cell culture medium was carefully removed. After rinsing in PBS, the cells were fixed in a freshly prepared solution of $4 \%$ paraformaldehyde for $30 \mathrm{~min}$. For immunofluorescent double staining, sections or cell cultures were preincubated with normal donkey serum (1:20; Jackson ImmunoResearch Laboratory) for $30 \mathrm{~min}$ and then incubated overnight with either mouse anti-A $\beta$ (1:500; Sigma-Aldrich) and rabbit anti-SYP (1:200; Sigma-Aldrich), or mouse anti-A $\beta$ and rabbit anti-HIF- $1 \alpha$ (1:200). After three washing with PBS, the immunoreactivity 
was probed using Texas-Red or fluorescein isothiocyanate (FITC) Green conjugated secondary antibodies (1:200; Jackson ImmunoResearch Laboratory) for $2 \mathrm{~h}$ at room temperature. After rinsing, the sections and cells were stained with DAPI for $5 \mathrm{~min}$. The images were observed by using a confocal laser scanning microscope (SP2, Leica). No fluorescence is expected to be detected when the primary antibody is omitted.

\section{Statistical Analysis}

All data are expressed as the mean \pm standard error (S.E.). Differences between means were evaluated with Student's $t$-test, and two-way ANOVA with Post hoc Fisher's Protected Least Significant Difference (PLSD) for cultured cells. All data were analyzed using SPSS 13.0 software, and statistical significance was assumed if $p<0.05$.

\section{Results}

\section{Intranasal DFO Treatment Modulated the Distribution of Fe in the Brains of APP/PS1 Mice}

We previously showed DFO did not attenuate the total content of Fe in brains tissues of APP/PS1 mice when it was administred (Guo et al., 2013a). In this study, brain sections from control and APP/PS1 mice that were intranasally administered DFO were subjected to Perl's-DAB analysis as a relative measure of Fe content within plaques and tissue. In general, Fe-positive plaques were distributed throughout the cortex and hippocampus in all examined animals (Figure 1), as previously described (Moreira et al., 2010). Fe deposits were observed as brown granules. In the cortex and hippocampus, many Fe-positive cells were detected, most of which were neurons with cytoplasmic Fe deposits, especially in the CA1 area of the hippocampus (Figure 1A). Importantly, $\mathrm{Fe}$ ions were only detected in the CA3 area of the hippocampus in untreated mice (Figure 1D), while no significant changes were observed in the cortex and the CA1 area of the hippocampus (Figures 1B,C). Thus, we can infer that mediating the redistribution of $\mathrm{Fe}$ rather than chelated $\mathrm{Fe}$ is probably responsible for inhibition of $\mathrm{APP} / \mathrm{A} \beta$ pathology in the brains of DFO-treated APP/PS1 transgenic mice.

\section{Intranasal DFO Treatment Reduced Synapse Loss in APP/PS1 Mouse Brains}

Previous studies have proposed that intranasal DFO administration reduced the expression and phosphorylation of APP protein by shifting the processing of APP to the nonamyloidogenic pathway. This reduction was accompanied by an attenuation of both the $\mathrm{A} \beta$ burden and tau phosphorylation, and memory retention was significantly promoted in APP/PS1 mice (Guo et al., 2013a,b). In the present study, we then assessed the effects of DFO on synapse lesion. As shown in Figures 2A,B, Western blot analysis showed that DFO treatment significantly increased the expression level of SYP compared with control group. As further evidence of that, the positive area of SYP staining was increased accompanied with a decreased immunoreactive area of $\mathrm{A} \beta$ plaque in the brain of $\mathrm{DFO}$-treated
APP/PS1 mice, compared with controls (Figure 2C). These results suggest that intranasal DFO treatment reduce synapse loss, and has a neuroprotective effect on the brain of APP/PS1 transgenic mice.

\section{Effect of DFO on the Expression of HIF-1 $\alpha$ and Proteins that are Encoded from HIF-1-Adaptive Genes in the Brains of APP/PS1 mice}

The potential therapeutic effect of a Fe-chelating compound may involve the activation of Fe-dependent prolyl hydroxylases, which regulate HIF stability, leading to transcriptional upregulation of a cassette of target genes. In turn, the upregulation of these genes could contribute to neuroprotection (Wang et al., 1995; Zaman et al., 1999). To investigate the role of DFO in HIF- $1 \alpha$ gene regulation, we first determined the mRNA levels of HIF-1 $\alpha$ in APP/PS1 mice brains by RTPCR analyses. As shown in Figure 3, the expression levels of both HIF-1 $\alpha$ protein (Figures 3A,B) and mRNA (Figures 3C,D) were significantly increased after intranasal DFO treatment, compared with the control mice $(p<0.01)$, indicating that the drugs not only stabilized HIF- $1 \alpha$ protein but influenced its transcriptional regulation. Immunohistochemical staining strengthened the biochemical results and further revealed that intranasal DFO treatment caused not only accumulation but also nuclear translocation of HIF- $1 \alpha$ (Figure 3E). The HIF- $1 \alpha$ expressed in the control was almost exclusively distributed in the cytoplasm of the neurons and rarely found in the nucleus. In contrast, cells of the DFO-treated group in the cortex and dentate gyrus of the hippocampus expressed high levels of HIF- $1 \alpha$ in both the cytoplasm and nucleus (Figure 3E).

Altogether, these results suggest that DFO has a positive effect on HIF-1 $\alpha$ gene and protein expression in the APP/PS1 mouse brain.

To determine whether DFO-induced HIF- $1 \alpha$ was transcriptionally active, we further examined the effects of DFO on the expression levels of selected downstream target proteins of HIF- $1 \alpha$ that might be involved in mediating Fe metabolism and neuroprotection. Quantitative analyses of Western blots revealed that treatment of APP/PS1 mice with DFO significantly up-regulated the expression of BDNF, DMT1 + IRE, and TFR proteins $(p<0.01$; Figures $\mathbf{3 F}-\mathbf{H}, \mathbf{J})$, whereas there were no significant changes in the expression levels of DMT1-IRE protein between the DFO-treated and control groups $(p>0.05$; Figures 3F,I). These results are consistent with previous reports demonstrating that Fe deficiency results in HIF-1 $\alpha$ stabilization and the up-regulation of several HIF-dependent adaptive genes, thereby coordinating the response to hypoxia conditions (Wang et al., 1995; Soucek et al., 2003).

\section{Effects of DFO on HIF-1 $\alpha$ Regulatory Pathways}

It has been reported that the mitogen-activated protein kinase (MAPK) signaling pathway and phosphatidylinositol3-kinase $(\mathrm{PI} 3 \mathrm{~K}) / \mathrm{AKT}$ signaling play important roles in regulating HIF-1 $\alpha$ expression (Blancher et al., 2001; Jiang et al., 2001). Here, we investigated the activation of the three MAPKs by Western blot analysis using phosphorylationspecific MAPK antibodies in DFO-treated APP/PS1 mice 


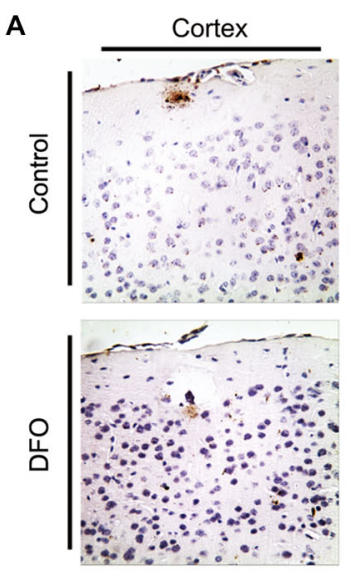

B

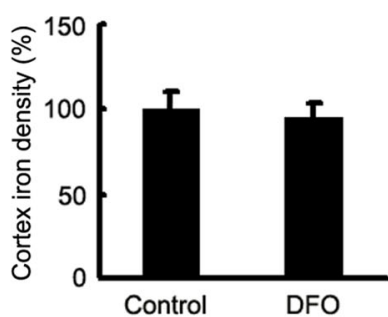

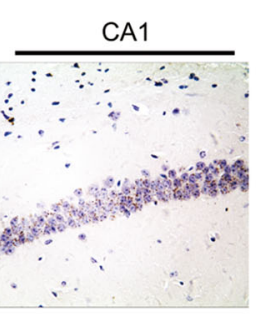

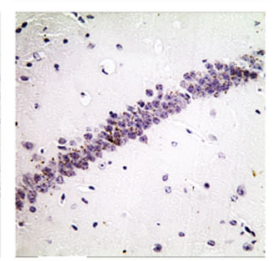

C

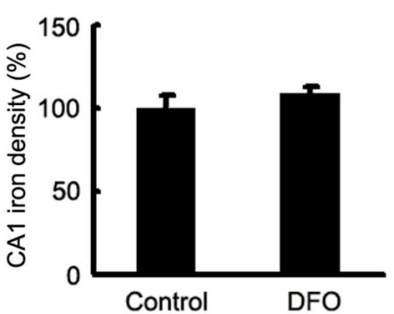

\section{CA3}
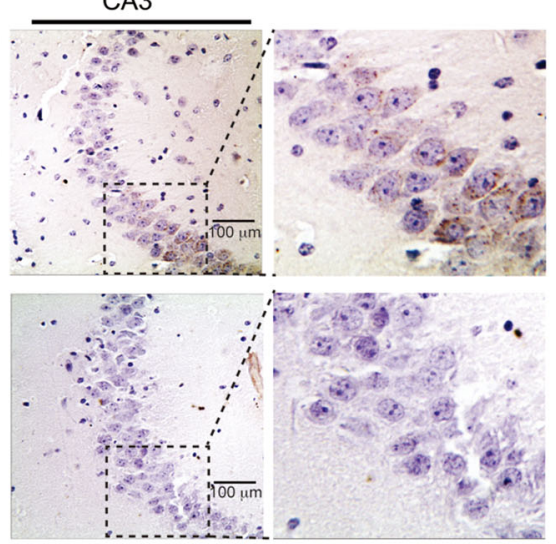

D
FIGURE 1 | Fe accumulation in the cortex and hippocampus of APP/PS1 mice. (A) APP/PS1 transgenic mice were treated with control or DFO

(200 mg/kg) for 3 months before sacrifice. The right hemisphere of the brains were quickly dissected, fixed in 4\% paraformaldehyde in phosphate buffered saline at $4^{\circ} \mathrm{C}$ overnight, embedded in paraffin, cut into sections $(5 \mu \mathrm{m})$ and stained with modified Perl's-DAB to reveal the distribution patterns of Fe ions in the cortex and hippocampus. Fe deposits can be observed as brown granules.
In the cortex and hippocampus, there are many Fe-positive cells, most of which are neurons with cytoplasmic Fe deposits, especially CA1 area of hippocampus. Importantly, Fe ions were only detected in the CA3 area of the hippocampus untreated mice. (B-D) Bar graphs illustrating the semi-quantitative Fe ions densitometry measurements as percentages of the intact side. Scale bar $=100 \mu \mathrm{m}$. These images are representative of 6 independent experiments, all revealing similar results. ${ }^{\star \star} P<0.01$ vs. control group.
(Figure 4). Treatment with DFO induced a significant decrease in phosphorylated ERK and JNK levels $(p<0.05$, Figure 4A; $p<0.01$, Figure 4B). However, treatment with DFO significantly increased the levels of p-P38 MAPK $(p<0.01$, Figure 4C) without affecting the total amounts of ERK, JNK, and P38 MAPK proteins (Figure 4). These results suggest that DFO-induced HIF- $1 \alpha$ protein accumulation was, at least in part, dependent on P38MAPK-mediated signaling pathway.

\section{DFO Inhibits A $\beta$ Generation Involved in HIF-1 $\alpha$ Stabilization and the Expression of Proteins that are Encoded Form HIF-1-Adaptive Genes in APPsw Cells}

To further investigate the mechanism underlying DFO-mediated up-regulation of HIF- $1 \alpha$ and the neuroprotective effect, we examined the effects of DFO against ferrous Fe-induced toxicity using Western blot analysis in vitro. To avoid the influence of cell death in the following experiments, we have previously explored the optimal concentrations of Fe and DFO, as following: $100 \mu \mathrm{M}$ ferrous sulfate and/or $100 \mu \mathrm{M}$ DFO (Guo et al., 2013a). As shown in Figure 5, there were no significant differences at the protein levels of HIF-1 $\alpha$, BDNF, DMT1 +
IRE, and TFR between the Fe group and the control cells. However, in DFO-treated cells, chelation of Fe with $100 \mu \mathrm{M}$ DFO significantly increased the expression levels of HIF-1 $\alpha$, BDNF, DMT1 + IRE, TFR proteins, respectively, compared with the control cells $(F=7.014 ; F=18.327 ; F=15.216$; $F=8.835 ; p<0.01$; Figures 5E,F,H,I,K). Notably, HIF-1 $\alpha$ and DMT1 proteins in the $\mathrm{Fe}+$ DFO-treated cells were significantly increased compared with their levels in control cells $(p<0.01$; Figures 5E,F,I). In addition, no differences in the expression levels of DMT1-IRE were found between the controls and any of the treatments $(F=1.965 ; p>0.05$; Figures 5E,J).

Next, we also performed Western blot analysis to determine the protein levels of APP695 in cells treated with DFO and/or Fe. Immunoblotting revealed that, compared with controls, treatment with $\mathrm{Fe}$ resulted in significantly increased levels of APP695 protein $(F=11.590 ; p<0.01$, Figures 5E,G). In contrast, the expression levels of APP695 in the DFO group were significantly decreased compared with controls $(p<0.01$; Figures 5E,G). Moreover, these increases were abolished when the cultures were treated with Fe followed by DFO ( $F=20.819 ; p<0.01$; Figures 5E,G). Double labeling of $\mathrm{A} \beta$ (Figures 5A2-D2) and HIF-1 $\alpha$ (Figures 5A1-D1) 
A

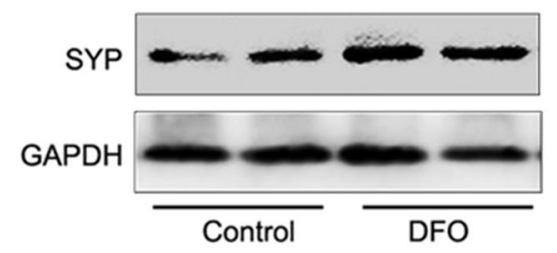

C
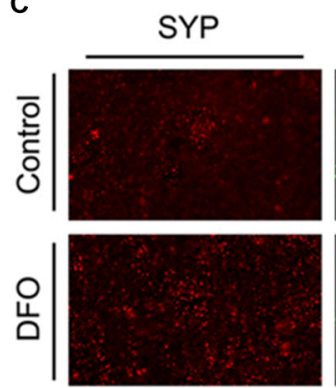
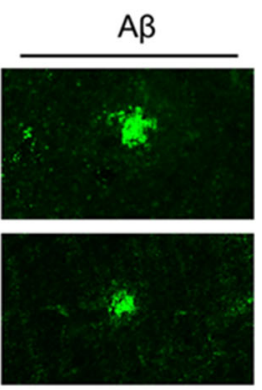

B
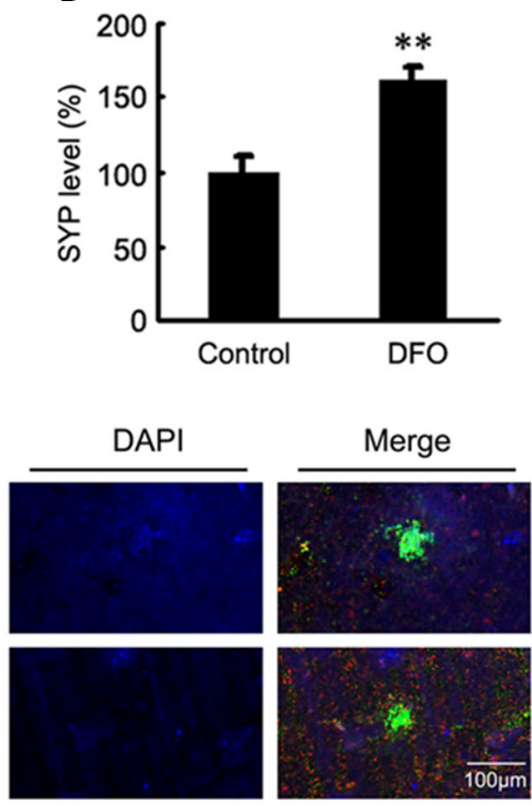

FIGURE 2 | Intranasal DFO treatment reduced synapse loss in APP/PS1 mouse brain. $(\mathbf{A}, \mathbf{B})$ Western blot analysis showed that DFO treatment significantly increased the expression level of SYP compared with control group. GAPDH was used as a loading control. (C) Immunofluorescence labeling and confocal microscopy analysis showing the distribution and expression of SYP (red) and A (green) in brain sections of APP/PS1 mice. The positive area of SYP staining was significantly increased following a decreased immunoreactive area of $A \beta$ plaque in the brain of DFO-treated APP/PS1 mice, compared with controls. Scale bar $=100 \mu \mathrm{m}$. Data represent the mean \pm S.E. of 6 independent experiments. ${ }^{\star \star} P<0.01$ vs. control group. showed that treatment with $\mathrm{Fe}$ significantly increased the A $\beta$ immunofluorescence in APPsw cells compared with the control (Figures 5A1,A2,B1,B2). DFO treatment decreased the immunofluorescence intensity of $A \beta$ but increased HIF-1 $\alpha$ immunoreactive intensity (Figures 5C1,C2) when the cells were treated with Fe and DFO. Levels of HIF- $1 \alpha$ were detected in both the cytoplasm and the nucleus in the DFO-treated cells. These results suggest that DFO has an inhibitory effect on APP695 protein expression and $\mathrm{A} \beta$ formation is involved in HIF-1 $\alpha$ stabilization in APPsw cells.

Collectively, these results further suggest that DFO significantly induces HIF- $1 \alpha$ accumulation, and promotes nuclear translocation, and then suppresses the $\mathrm{A} \beta$ generation.

\section{DFO up-Regulate HIF-1 $\alpha$ Protein by the Activation of P38 MAPK in APPsw Cells}

To test the hypothesis that DFO may up-regulate the HIF-1 $\alpha$ signaling cascades by P38 MAPK activation in APPsw cells, we further investigated the effect of DFO on the activation of intracellular signaling proteins in APPsw cells. As shown in Figure 6, strong phosphorylation of P38 MAPK was detected in the DFO-treated cells $(F=5.321$; $p<0.01$; Figures 6A,B), whereas no significant changes were observed in cells treated with $\mathrm{Fe}$ alone compared with the control group. Interestingly, the total P38 MAPK protein level, were not changed among the groups $(p>0.05$; Figures 6A,B).
Then, inhibition studies were carried out to investigate the effect of signaling proteins in the DFO-mediated up-regulation of HIF- $1 \alpha$. For this, APPsw cells were treated without or with DFO in the absence or presence of SB203580. Immunoblotting showed that DFO treatment at $24 \mathrm{~h}$ significantly increased the phosphorylation of P38 MAPK compared with the control group, whereas the increase was significantly ameliorated by SB203580 $(p<0.01$; Figures 6C,D). Profoundly, as shown in Figures 6C,E, the DFO-mediated up-regulation of HIF-1 $\alpha$ protein in APPsw cells was greatly inhibited followed by the pretreatment with SB203580.

Taken together, these data suggest that activities of P38 MAPK, specifically the phosphorylation of P38 MAPK, contribute to the increased expression and activity of HIF-1 $\alpha$ protein in APPsw cells upon DFO treatment.

\section{Discussion}

$\mathrm{DFO}$ is a $\mathrm{Fe}$ chelator that has been shown to prevent $\mathrm{AD}$ in a clinical trial and a range of disease models (Crapper McLachlan et al., 1991; Savory et al., 1998; Morse et al., 2004; Fine et al., 2012; Guo et al., 2013a,b). Our previous studies have demonstrated that intranasal DFO treatment reverses Fe-induced memory defects and inhibits amyloidogenic APP processing and tau hyperphosphorylation in APP/PS1 mice (Guo et al., 2013a,b). Despite these important advances, the mechanisms of DFO-induced neuroprotection are not completely understood. This present study was designed to address the mechanism of intranasal DFO-induced 
A

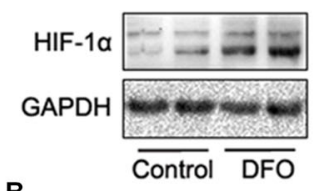

B

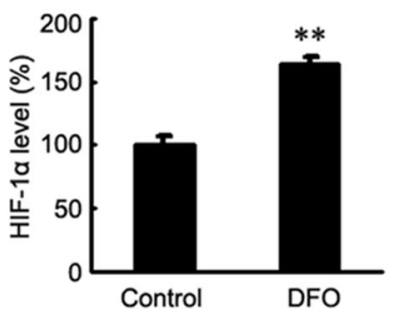

$\mathbf{F}$

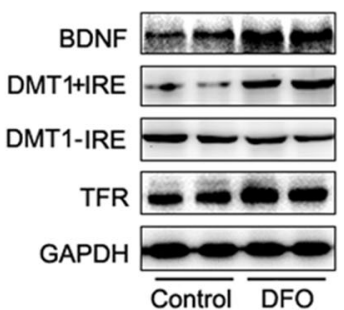

G
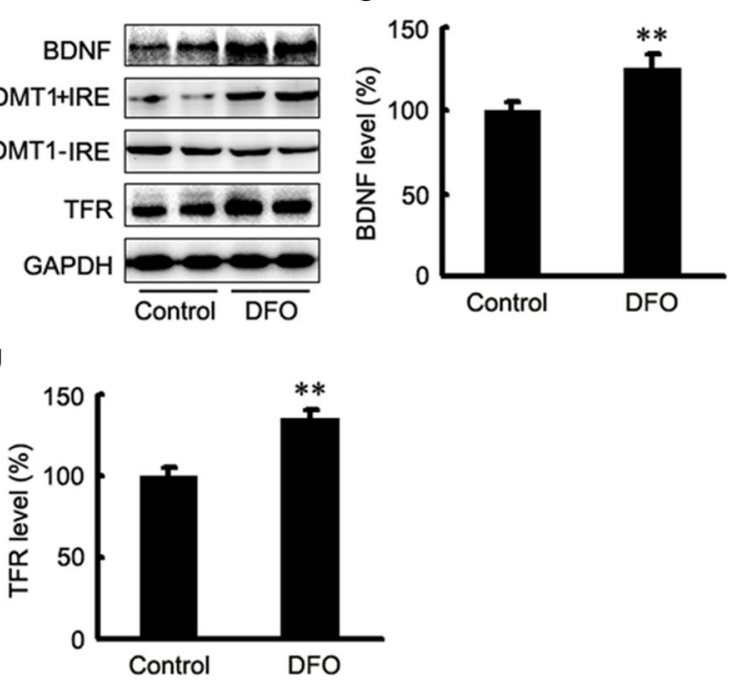

FIGURE 3 | DFO regulates the expression of HIF- $1 \alpha$ and HIF-1-related protein in the brains of APP/PS1 mice.

(A) Western blots showing the expression levels of $\mathrm{HIF-1} \alpha$ protein in control and DFO-treated transgenic mice brains. (B) Immunoblot showed that DFO treatment significantly increased HIF-1 $\alpha$ protein levels, compared with controls. (C) The expression levels of HIF-1 $1 \alpha$ mRNA were detected by RT-PCR in the brains of APP/PS1 transgenic mice treated with DFO. (D) RT-PCR analysis showed that DFO treatment significantly increased the HIF-1 $\alpha$ mRNA levels in the transgenic mouse brain. GAPDH served as the internal control.

(E) Immunohistochemically stains showed the distribution of HIF-1 $\alpha$ in

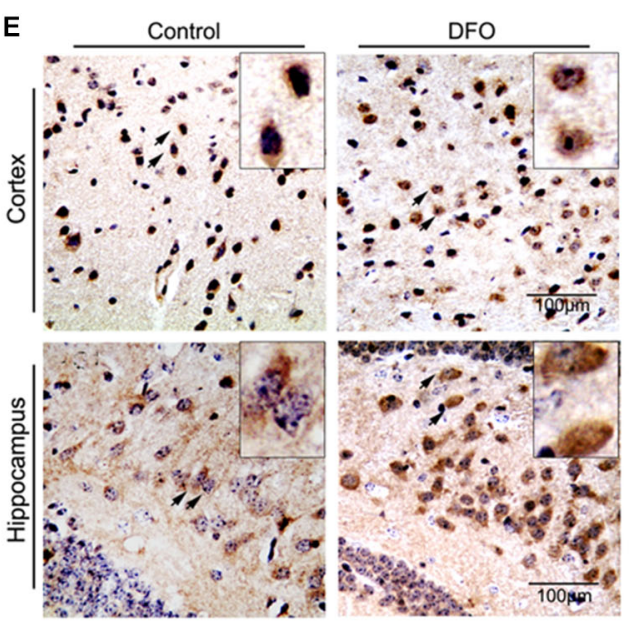

H
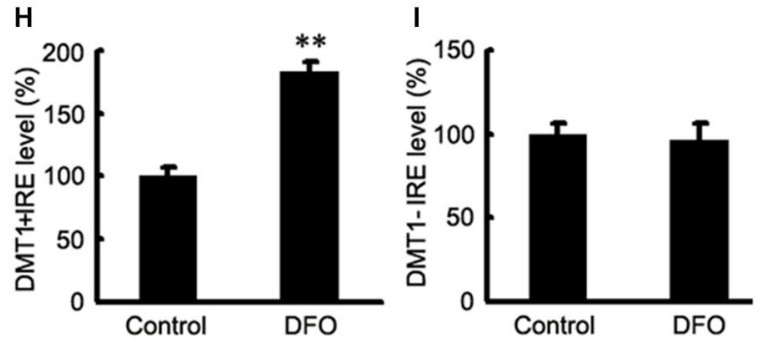

hypoxia signaling to further our understanding of the therapeutic action of this agent in $\mathrm{AD}$ pathogenesis. DFO treatment decreases the $A \beta$ deposition and reduces the synapse loss. More importantly, we extend previous observations and demonstrate that DFO-induced HIF- $1 \alpha$ stabilization regulates $\mathrm{Fe}$ homeostasis and is a target for neuroprotection. These neuroprotective mechanisms include functional activation of HIF-1 signaling and regulation of wide range of HIF-1-related adaptive proteins, such as DMT1 + IRE, TFR and BDNF. Consequently, we have now identified important roles of the P38 MAPKs in the intranasal the cortical and hippocampus sections of APP/PS1 mouse brain (Scale bar $=100 \mu \mathrm{m})$. (F) Western blots showing the expression levels of brain-derived neurotrophic factor (BDNF), DMT1, and TFR proteins in APP/PS1 transgenic mice brains 3 months after DFO administration. GAPDH was used as a loading control. (G-J) DFO treatment led to a marked increase in the BDNF, DMT1 + IRE, and TFR protein levels in the brains of transgenic mice compared with the control. There was no significant change in the expression levels of DMT1-IRE protein between the groups, compared with the control. Data represent the mean \pm S.E. of 6 independent experiments. ${ }^{\star \star} P<0.01$ vs. control group.
DFO-induced HIF-1 $\alpha$ upregulation in APP/PS1 mice and APPsw cells.

Fe chelators, which can possess $\mathrm{Fe}$ chelating ability for removal of excess $\mathrm{Fe}$ in the brain, have the potential for clinical use in neurological disorders, therefore, they have been suggested as a potential noninvasive strategy for the treatment of AD (Hanson et al., 2009; Fine et al., 2012; Guo et al., 2013a). In this study, we found that Fe-containing cells in the cortex and the CA1 area of hippocampus did not significantly differ in amounts between the DFO-treated and the control mice, whereas the levels of $\mathrm{Fe}$ in the Fe-positive 


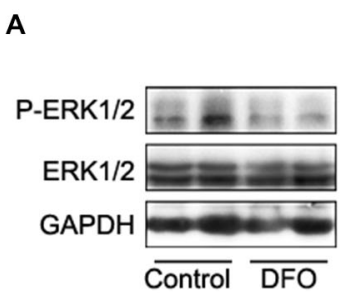

B

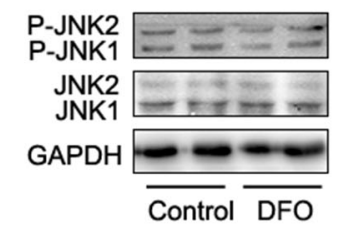

C

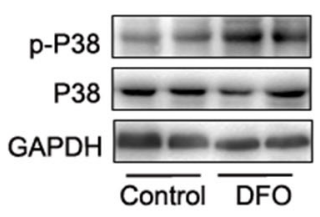

A1

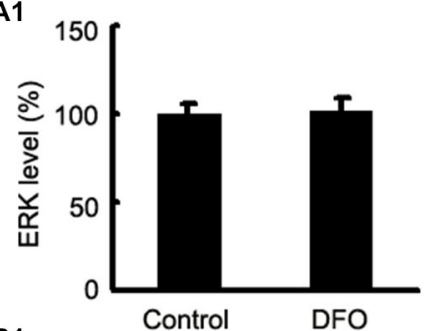

B1

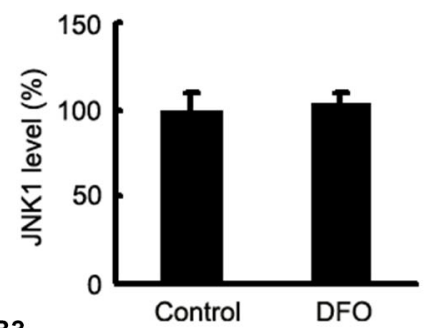

B3

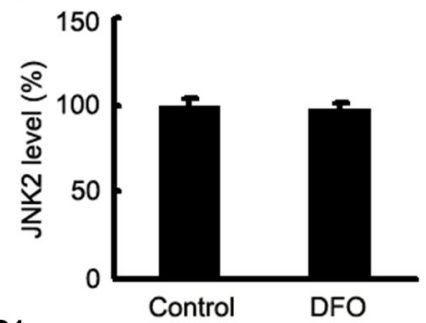

C1

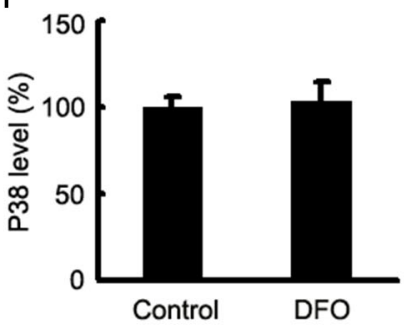

A2

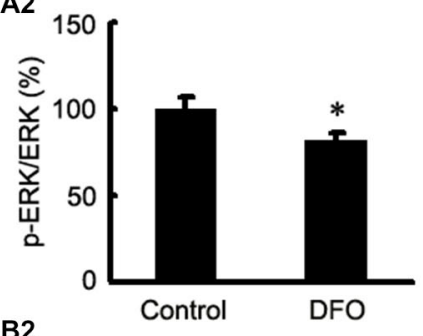

B2

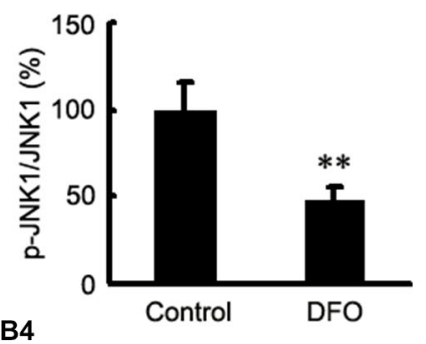

B4

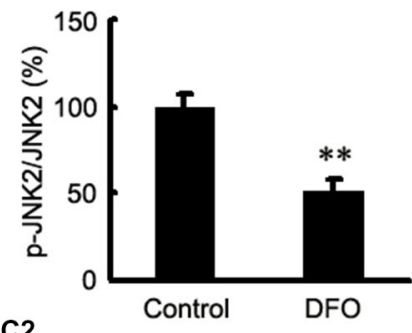

C2

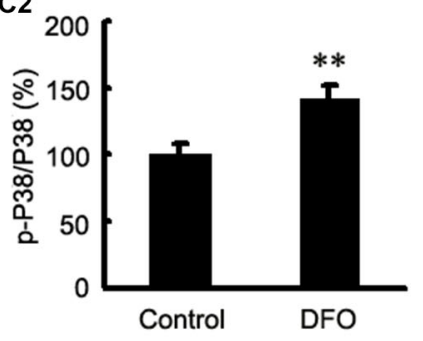

FIGURE 4 | Expression levels of ERK, JNK, and P38 in the brains of APP/PS1 mice 3 months after DFO treatment. (A) Western blots showing the protein levels of ERK1/2 in the brains of transgenic mice. (A1,A2) There were no significant differences in total ERK $1 / 2$ levels between the brains of control and DFO-treated. However, the ratio of $p$-ERK $1 / 2$ to ERK $1 / 2$ was significantly decreased after DFO treatment. (B) Immunoblot analyses showing the expression levels of JNK1/2 in the brains of transgenic mice. (B1-B4) A marked reduction in the ratio of $\mathrm{p}-\mathrm{JNK} 1 / 2$ to $\mathrm{JNK} 1 / 2$ was detected in the brains of DFO-treated mice, whereas there were no significant differences in total JNK1/2 levels between the brains of control and DFO-treated mice. (C) Western blots showing the protein levels of P38 in the brains of transgenic mice. (C1,C2) There were no significant differences in total P38 levels between the brains of control and DFO-treated mice. However, the ratio of p-P38 to P38 was markedly increased after DFO treatment. GAPDH was used as an internal control. Data represent the mean \pm S.E. of 6 independent experiments. ${ }^{*} p<0.05,{ }^{* *} p<0.01$ vs. control group. cells in DFO-treated mice were significantly reduced in the CA3 area of the hippocampus. Therefore, we presume that the redistribution of $\mathrm{Fe}$, rather than the removal of Fe from the system, is most likely responsible for the neuroprotective functions of DFO.

Recently, alternative mechanisms involving chelator exposure were proposed for example, Fe chelator exposure can induce the cellular stress response by activating adaptive signaling proteins such as HIF-1 $\alpha$. This response triggers gene expression shifts that increase the ability of the cell to tolerate elevated levels of oxidative stress, and more importantly, cellular $\mathrm{Fe}$ dyshomeostasis (Lee and Andersen, 2006). Indeed, previous in vitro studies demonstrated that $\mathrm{DFO}$ treatment may cause a decrease in mitochondrial reactive oxygen species (ROS) levels in primary neurons, which then act as signaling molecules for HIF-1 activation (Bianchi et al., 1999; Zaman et al., 1999; Honda et al., 2005; Siddiq et al., 2005); the induction of HIF- $1 \alpha$ activation and gene signaling associated with $\mathrm{Fe}$ homeostasis and metabolism (Lee et al., 1997; Rolfs et al., 1997). The current study demonstrated that intranasal DFO administration induced the mRNA expression of HIF- $1 \alpha$ and increased protein levels of HIF-1 $\alpha$ in APP/PS1 mouse brains. Subsequently, DFO significantly up-regulated the expression levels of several adaptive HIF-1-related genes, such as BDNF 

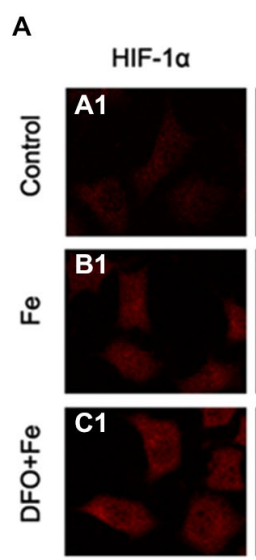

임

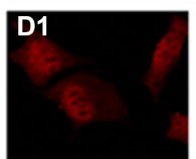

$\mathbf{F}$

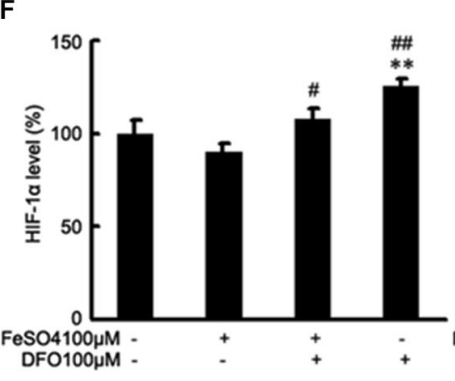

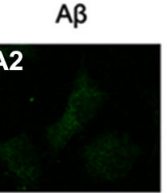
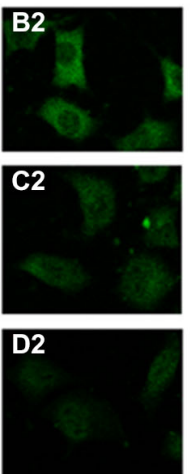

\section{DAPI}

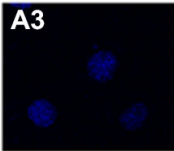

B3
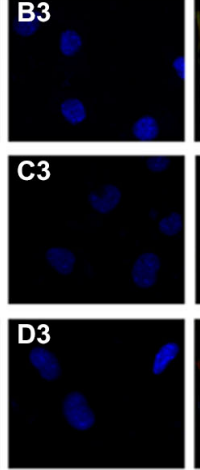

G
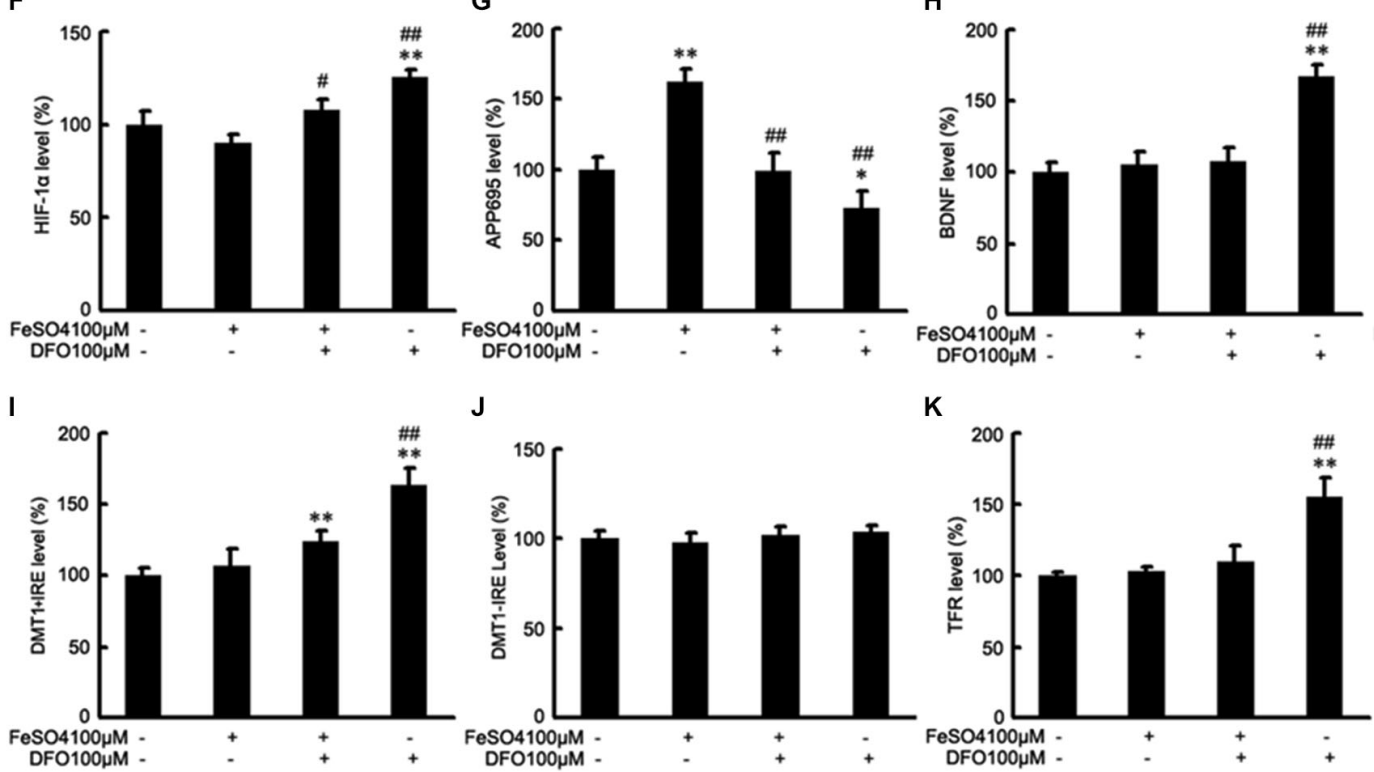

J
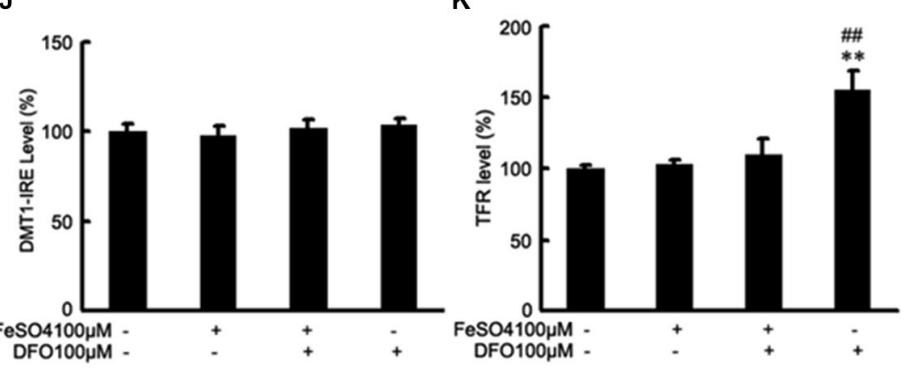

FIGURE 5 | DFO inhibits A $\beta$ generation involved in HIF-1 $\alpha$ stabilization and the expression of proteins that are encoded form HIF-1-adaptive genes in APPsw cells. (A) Immunofluorescence labeling and confocal microscopy analysis showing the distribution and expression of $\mathrm{HIF}-1 \alpha$ (A1-D1) and A $\beta$ (A2-D2) in APPsw cells. DFO treatment significantly increased the HIF-1 $\alpha$ immunofluorescence (D1) and reduced the $A \beta$ immunofluorescence (D2) in APPsw cells compared with the control (A1,A2). (A3-D3) DAPI was used to detect the nucleus (blue). (A4-D4) Merged images from the double channels indicated that DFO has an inhibitory effect on $A \beta$ formation is involved in HIF-1 $\alpha$ stabilization in APPsw cells. Fe treatment $(100 \mu \mathrm{M})$ decreased the levels of HIF-1 $\alpha$ (B1) and increased the $A \beta$ immunofluorescence (B2). The additional of DFO treatment reversed the reduction of HIF-1 $\alpha(\mathbf{C} 1)$ and the increase of $A \beta(\mathbf{C} 2)$ in cultures pretreated with $100 \mu \mathrm{M}$ Fe. The images are a representative of three independent experiments. Scale bar $=20 \mu \mathrm{m}$. (E) Western blot

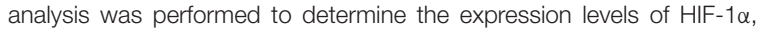
APP695, BDNF, DMT1, and TFR; GAPDH served as the internal control. (F)
E

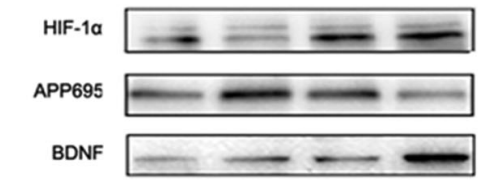

DMT1+IRE

DMT1-IRE

TFR

GAPDH

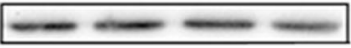

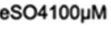

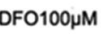

$\mathrm{H}$

K

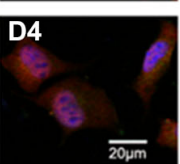

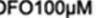

There were no significant changes in $\mathrm{HIF-1} \alpha$ levels in the $\mathrm{Fe}$ - or $\mathrm{Fe}+\mathrm{DFO}$-treated groups compared with the controls. HIF-1 $\alpha$ was markedly increased after DFO treatment. In the Fe + DFO group, the level of HIF-1 $\alpha$ was significantly increased compared with that in the Fe treatment group. (G) Fe treatment significantly increased the levels of APP695. In the Fe + DFO group, the levels of APP695 were significantly decreased compared with the Fe treatment group. DFO treatment significantly reduced the expression level of APP695 compared with their levels in the controls. (H-K) There were no significant changes in BDNF, DMT1 + IRE, and TFR levels in the Fe-treated groups, whereas the level of DMT1 + IRE was significantly increased in the Fe + DFO compared with the controls. The level of BDNF, DMT1 + IRE, and TFR was significantly increased in the DFO group, compared with the controls. No differences in the expression levels of DMT1-IRE were found between the controls and any of the treatments. Data represent the mean \pm S.E. $(n=3) .{ }^{*} p<0.05,{ }^{* *} p<0.01$ compared with the control group; ${ }^{\#} p<0.05,{ }^{\# \#} p<0.01$ compared with the $\mathrm{Fe}$ treatment group (two-way ANOVA with Post hoc Fisher's PLSD). and the Fe homeostasis/metabolism protein DMT1 + IRE, TFR, implying an additional neuroprotective mechanism of
DFO: induction of HIF-1 $\alpha$ and regulation of Fe metabolism in vivo (Semenza, 1998; Bergeron et al., 1999). These results 

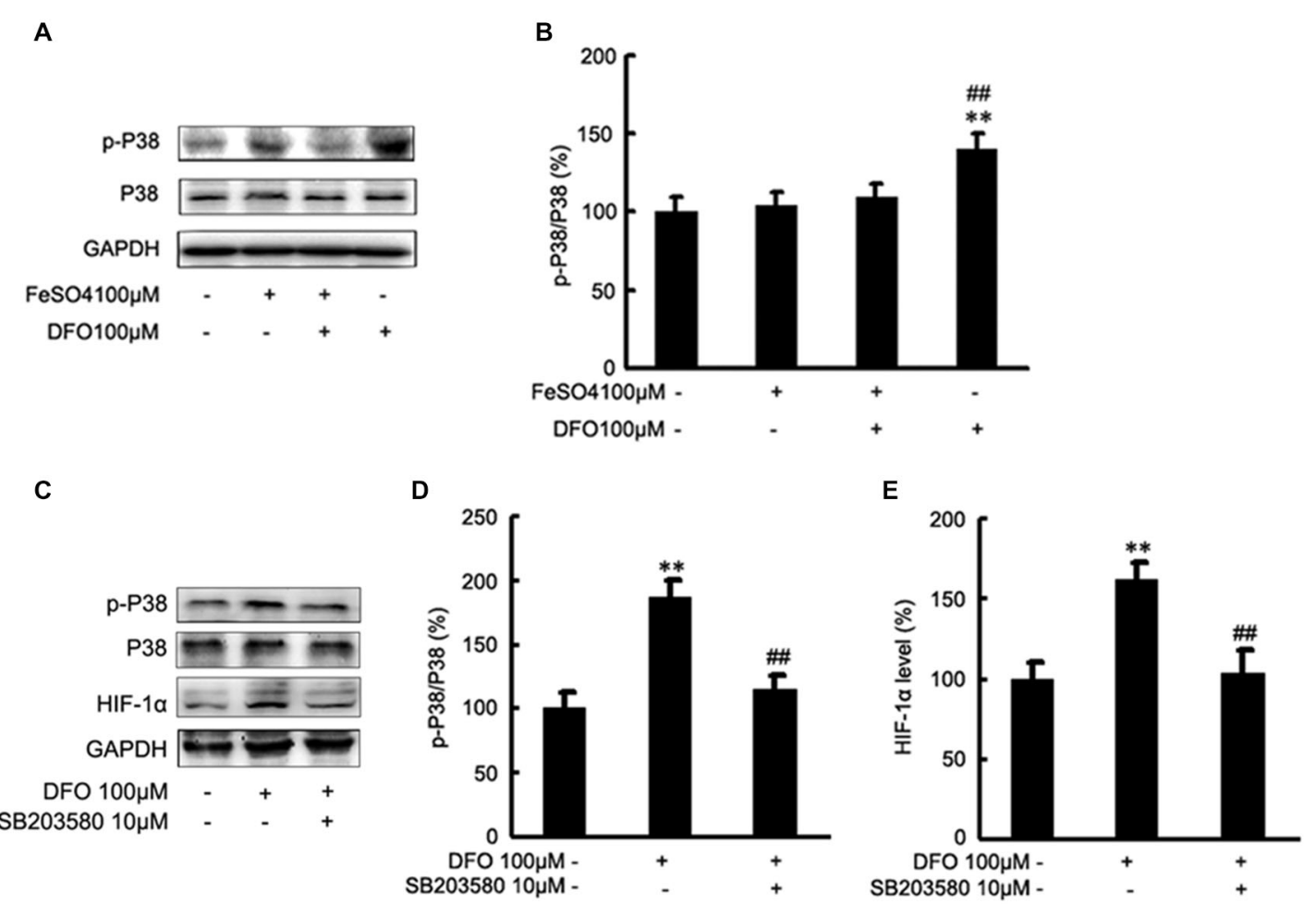

FIGURE 6 | Roles of P38 mitogen-activated protein kinase (MAPK) in the DFO-mediated up-regulate of HIF-1 $\alpha$ protein in APPsw cells. (A) APPsw were exposed to $100 \mu \mathrm{M} \mathrm{Fe}, 100 \mu \mathrm{M}$ DFO, or both combined for $24 \mathrm{~h}$. Whole cell lysates were prepared and subjected to analysis for P38 or GAPDH protein. (B) Western blot analysis revealed that strong phosphorylation of P38 MAPK was detected in the DFO-treated cells, whereas no significant changes were observed in cells treated Fe alone compared with control. There were not statistical changes in the levels of P38 MAPK among the groups. The data represent the mean \pm S.E. of three independent experiments. ${ }^{*} p<0.05,{ }^{* *} p<0.01$ compared with the control:
${ }^{\#} p<0.05,{ }^{\# \#} p<0.01$ with respect to the Fe treatment group. (C-E) APPsw cells were pretreated without or with SB203580 (10 $\mu \mathrm{M})$ for $2 \mathrm{~h}$ and then treated without or with DFO for additional $22 \mathrm{~h}$ in the absence or presence of the inhibitor. Immunoblotting showed that DFO treatment significantly increased the levels of p-P38 MAPK compared with the control group, whereas the increase was significantly ameliorated by SB203580. Furthermore, the DFO-mediated up-regulation of HIF-1 $\alpha$ protein was greatly inhibited by SB203580. The data represent the mean \pm S.E. $(n=3) .{ }^{* *} p<0.01$ compared with the control; ${ }^{\# \#} p<0.01$ compared to the values of DFO treatment group (two-way ANOVA with Post hoc Fisher's PLSD). are further supported by the findings that increased levels of HIF- $1 \alpha$ were detected in both the cytosol and the nucleus of cortical and hippocampal neurons in the DFO-treated group. Additionally, studies with SH-SY5Y cells in vitro demonstrated that epigallocatechin-3-gallate (EGCG) was to confer neurorescue effects and significantly up-regulate the expression of HIF-1 and its target gene TFR, the latter is associated with Fe homeostasis (Reznichenko et al., 2006; Weinreb et al., 2008). Interestingly, our study also demonstrated that DFO elevates BDNF protein levels, which promotes neuronal survival and differentiation (Thoenen, 1995, 2000; Schinder and Poo, 2000). It also was reported that M30 increases the expression levels of BDNF transcripts (Avramovich-Tirosh et al., 2010), thereby inhibiting hypoxia-induced apoptosis (Ruscher et al., 2002). To further corroborate the role of HIF- $1 \alpha$ in the pathogenesis of $\mathrm{AD}$, we embarked in a series of in vitro experiments. In accordance, our in vitro findings demonstrated that DFO up-regulated expression of HIF-1 $\alpha$ and several HIF- $1 \alpha$ target proteins in APPsw cells, which was accompanied by a reduction in APP695 protein expression and $A \beta$ generation. This can be viewed that the regulation of HIF- $1 \alpha$ expression and its related targets may constitute an additional pathway underlying the neuroprotective effect of DFO.

Notably, the modulation of the HIF pathway appears to be complex. Some proteins have been shown to stimulate HIF-1 $\alpha$ transactivation or synthesis by activation of the MAPK or the PI3K signaling pathways (Zelzer et al., 1998; Li et al., 2004; Lonati et al., 2014). To elucidate the molecular mechanism for the DFO induced HIF- $1 \alpha$ stabilization and activation, we evaluated the total and activated forms of ERK1/2, JNK1/2, and P38 because they have been also implicated in involving APP processing with increased A $\beta$ deposition (Atkins et al., 1998; Savage et al., 2002; Kim et al., 2006; Cho et al., 2007; Lee et al., 2009). Here, we showed that the phosphorylation of ERK1/2 and JNK was attenuated in the DFO-treated group in vivo. Our data are in agreement with a very recent study describing that green tea catechin, an iron chelator, may decrease in behavioral impairment, $A \beta-42$ production, and activation of ERK and JNK MAPK in NSE/hAPP-C105 transgenic mice (Lim et al., 
2013). Interestingly, we observed that under our experimental conditions, DFO enhanced P38 MAPK phosphorylation in cultured APPsw cells and brains of treated APP/PS1 mice. It has been reported that different MAPKs are activated by different stimuli and target different downstream molecules; therefore, they each perform different functions (Schaeffer and Weber, 1999; Roux and Blenis, 2004). Therefore, these alterations in the expression of MAPK family members induced by DFO treatment provide vital information about the mechanism of $\mathrm{DFO}$ action during $\mathrm{AD}$ treatment. Further, we observed in vitro that inhibitors of P38 block HIF- $1 \alpha$ upregulation by DFO treatment. These results, and the demonstration of P38 MAPK elevation in both human APPsw cells and AD mouse brains, suggest that P38 MAPK is a central mediator of hypoxia-induced neuroprotection in $\mathrm{AD}$. The notion that $\mathrm{DFO}$ might regulate HIF-1 $\alpha$ via phosphorylation of MAPK/P38 signaling pathway will be addressed in greater depth in future studies.

\section{References}

Atkins, C. M., Selcher, J. C., Petraitis, J. J., Trzaskos, J. M., and Sweatt, J. D. (1998). The MAPK cascade is required for mammalian associative learning. Nat. Neurosci. 1, 602-609. doi: 10.1038/2836

Avramovich-Tirosh, Y., Bar-Am, O., Amit, T., Youdim, M. B., and Weinreb, O. (2010). Up-regulation of hypoxia-inducible factor (HIF)-1alpha and HIF-target genes in cortical neurons by the novel multifunctional iron chelator anti-Alzheimer drug, M30. Curr. Alzheimer Res. 7, 300-306. doi: 10. 2174/156720510791162403

Bandyopadhyay, S., Huang, X., Lahiri, D. K., and Rogers, J. T. (2010). Novel drug targets based on metallobiology of Alzheimer's disease. Expert Opin. Ther. Targets 14, 1177-1197. doi: 10.1517/14728222.2010.525352

Bergeron, M., Yu, A. Y., Solway, K. E., Semenza, G. L., and Sharp, F. R. (1999). Induction of hypoxia-inducible factor-1 (HIF-1) and its target genes following focal ischaemia in rat brain. Eur. J. Neurosci. 11, 4159-4170. doi: 10.1046/j. 1460-9568.1999.00845.x

Bianchi, L., Tacchini, L., and Cairo, G. (1999). HIF-1-mediated activation of transferrin receptor gene transcription by iron chelation. Nucleic Acids Res. 27, 4223-4227. doi: 10.1093/nar/27.21.4223

Blancher, C., Moore, J. W., Robertson, N., and Harris, A. L. (2001). Effects of ras and von Hippel-Lindau (VHL) gene mutations on hypoxia-inducible factor (HIF)-1alpha, HIF-2alpha and vascular endothelial growth factor expression and their regulation by the phosphatidylinositol $3^{\prime}$-kinase/Akt signaling pathway. Cancer Res. 61, 7349-7355.

Cho, H. J., Kim, S. K., Jin, S. M., Hwang, E. M., Kim, Y. S., Huh, K., et al. (2007). IFN-gamma-induced BACE1 expression is mediated by activation of JAK2 and ERK1/2 signaling pathways and direct binding of STAT1 to BACE1 promoter in astrocytes. Glia 55, 253-262. doi: 10.1002/glia. 20451

Crapper McLachlan, D. R., Dalton, A. J., Kruck, T. P., Bell, M. Y., Smith, W. L., Kalow, W., et al. (1991). Intramuscular desferrioxamine in patients with alzheimer's disease. Lancet 337, 1304-1308. doi: 10.1016/0140-6736(91) 92978-b

Cuajungco, M. P., Fagét, K. Y., Huang, X., Tanzi, R. E., and Bush, A. I. (2000). Metal chelation as a potential therapy for alzheimer's disease. Ann. $N$ Y Acad. Sci. 920, 292-304. doi: 10.1111/j.1749-6632.2000.tb06938.x

de Lima, M. N., Dias, C. P., Torres, J. P., Dornelles, A., Garcia, V. A., Scalco, F. S., et al. (2008). Reversion of age-related recognition memory impairment by iron chelation in rats. Neurobiol. Aging 29, 1052-1059. doi: 10.1016/j. neurobiolaging.2007.02.006

Epstein, A. C., Gleadle, J. M., McNeill, L. A., Hewitson, K. S., O’Rourke, J., Mole, D. R., et al. (2001). C. elegans EGL-9 and mammalian homologs define a family of dioxygenases that regulate HIF by prolyl hydroxylation. Cell 107, 43-54. doi: 10.1016/S0092-8674(01)00507-4
Taken together, the present results suggest that the neuroprotective effects of DFO may be correlated, at least in part, with the ability of this Fe chelator to activate the transcriptional activator HIF- $1 \alpha$ and up-regulate HIF- $1 \alpha$ mediated protective genes, especially these targets involving in Fe metabolism. Our data further indicate that HIF-1 may prevent $\mathrm{AD}$ occurrence, postpone $\mathrm{AD}$ progression, and ameliorate $\mathrm{AD}$ symptoms by regulating the expression of its target genes. Thus, Fe chelators, and specifically intranasal administration of DFO, might be beneficial for their potent efficacy in the prevention and treatment of neurodegenerative diseases such as AD.

\section{Acknowledgments}

The study was supported by the basic scientific research fund of Northeastern University (N120820001; N141008001/7).

Fine, J. M., Baillargeon, A. M., Renner, D. B., Hoerster, N. S., Tokarev, J., Colton, S., et al. (2012). Intranasal deferoxamine improves performance in radial arm water maze, stabilizes HIF-1alpha and phosphorylates GSK3beta in P301L tau transgenic mice. Exp. Brain Res. 219, 381-390. doi: 10.1007/s00221-0123101-0

Guo, C., Wang, T., Zheng, W., Shan, Z. Y., Teng, W. P., and Wang, Z. Y. (2013a) Intranasal deferoxamine reverses iron-induced memory deficits and inhibits amyloidogenic APP processing in a transgenic mouse model of Alzheimer's disease. Neurobiol. Aging 34, 562-575. doi: 10.1016/j.neurobiolaging.2012. 05.009

Guo, C., Wang, P., Zhong, M. L., Wang, T., Huang, X. S., Li, J. Y., et al. (2013b). Deferoxamine inhibits iron induced hippocampal tau phosphorylation in the Alzheimer transgenic mouse brain. Neurochem. Int. 62, 165-172. doi: 10.1016/j. neuint.2012.12.005

Haleagrahara, N., Siew, C. J., and Ponnusamy, K. (2013). Effect of quercetin and desferrioxamine on 6-hydroxydopamine (6-OHDA) induced neurotoxicity in striatum of rats. J. Toxicol. Sci. 38, 25-33. doi: 10.2131/jts.38.25

Hanson, L. R., Roeytenberg, A., Martinez, P. M., Coppes, V. G., Sweet, D. C., Rao, R. J., et al. (2009). Intranasal deferoxamine provides increased brain exposure and significant protection in rat ischemic stroke. J. Pharmacol. Exp. Ther. 330, 679-686. doi: 10.1124/jpet.108.149807

Honda, K., Smith, M. A., Zhu, X., Baus, D., Merrick, W. C., Tartakoff, A. M., et al. (2005). Ribosomal RNA in alzheimer disease is oxidized by bound redox-active iron. J. Biol. Chem. 280, 20978-20986. doi: 10.1074/jbc.m5005 26200

Ivan, M., Kondo, K., Yang, H., Kim, W., Valiando, J., Ohh, M., et al. (2001). HIFalpha targeted for VHL-mediated destruction by proline hydroxylation: implications for O2 sensing. Science 292, 464-468. doi: 10.1126/science. 1059817

Jaakkola, P., Mole, D. R., Tian, Y. M., Wilson, M. I., Gielbert, J., Gaskell, S. J., et al. (2001). Targeting of HIF-alpha to the von hippel-lindau ubiquitylation complex by O2-regulated prolyl hydroxylation. Science 292, 468-472. doi: 10. 1126/science.1059796

Jiang, B. H., Jiang, G., Zheng, J. Z., Lu, Z., Hunter, T., and Vogt, P. K. (2001) Phosphatidylinositol 3-kinase signaling controls levels of hypoxia-inducible factor 1. Cell Growth Differ. 12, 363-369.

Kim, S. K., Park, H. J., Hong, H. S., Baik, E. J., Jung, M. W., and Mook-Jung, I. (2006). ERK1/2 is an endogenous negative regulator of the gamma-secretase activity. FASEB J. 20, 157-159. doi: 10.1096/fj.05-4055fje

Lando, D., Peet, D. J., Whelan, D. A., Gorman, J. J., and Whitelaw, M. L. (2002). Asparagine hydroxylation of the HIF transactivation domain a hypoxic switch. Science 295, 858-861. doi: 10.1126/science.1068592

Lee, D. W., and Andersen, J. K. (2006). Role of HIF-1 in iron regulation: potential therapeutic strategy for neurodegenerative disorders. Curr. Mol. Med. 6, 883-893. doi: 10.2174/156652406779010849 
Lee, P. J., Jiang, B. H., Chin, B. Y., Iyer, N. V., Alam, J., Semenza, G. L., et al. (1997). Hypoxia-inducible factor-1 mediates transcriptional activation of the heme oxygenase-1 gene in response to hypoxia. J. Biol. Chem. 272, 5375-5381. doi: $10.1074 / \mathrm{jbc} .272 .9 .5375$

Lee, J. W., Lee, Y. K., Ban, J. O., Ha, T. Y., Yun, Y. P., Han, S. B., et al. (2009). Green tea (-)-epigallocatechin-3-gallate inhibits beta-amyloid-induced cognitive dysfunction through modification of secretase activity via inhibition of ERK and NF-kappaB pathways in mice. J. Nutr. 139, 1987-1993. doi: 10. 3945/jn.109.109785

Li, J., Davidson, G., Huang, Y., Jiang, B. H., Shi, X., Costa, M., et al. (2004). Nickel compounds act through phosphatidylinositol-3-kinase/ Akt-dependent, p70(S6k)-independent pathway to induce hypoxia inducible factor transactivation and Cap43 expression in mouse epidermal Cl41 cells. Cancer Res. 64, 94-101. doi: 10.1158/0008-5472.can-03-0737

Lim, H. J., Shim, S. B., Jee, S. W., Lee, S. H., Lim, C. J., Hong, J. T., et al. (2013). Green tea catechin leads to global improvement among Alzheimer's disease-related phenotypes in NSE/hAPP-C105 Tg mice. J. Nutr. Biochem. 24, 1302-1313. doi: 10.1016/j.jnutbio.2012.10.005

Lonati, E., Brambilla, A., Milani, C., Masserini, M., Palestini, P., and Bulbarelli, A. (2014). Pin1, a new player in the fate of HIF-lalpha degradation: an hypothetical mechanism inside vascular damage as Alzheimer's disease risk factor. Front. Cell. Neurosci. 8:1. doi: 10.3389/fncel.2014.00001

Mecklenburgh, K. I., Walmsley, S. R., Cowburn, A. S., Wiesener, M., Reed, B. J., Upton, P. D., et al. (2002). Involvement of a ferroprotein sensor in hypoxiamediated inhibition of neutrophil apoptosis. Blood 100, 3008-3016. doi: 10. 1182/blood-2002-02-0454

Migliore, L., and Coppedè, F. (2009). Environmental-induced oxidative stress in neurodegenerative disorders and aging. Mutat. Res. 674, 73-84. doi: 10.1016/j. mrgentox.2008.09.013

Moreira, P. I., Sayre, L. M., Zhu, X., Nunomura, A., Smith, M. A., and Perry, G. (2010). Detection and localization of markers of oxidative stress by in situ methods: application in the study of Alzheimer disease. Methods Mol. Biol. 610, 419-434. doi: 10.1007/978-1-60327-029-8_25

Morse, L. J., Payton, S. M., Cuny, G. D., and Rogers, J. T. (2004). FDApreapproved drugs targeted to the translational regulation and processing of the amyloid precursor protein. J. Mol. Neurosci. 24, 129-136. doi: 10.1385/jmn: 24:1:129

Reznichenko, L., Amit, T., Zheng, H., Avramovich-Tirosh, Y., Youdim, M. B., Weinreb, O., et al. (2006). Reduction of iron-regulated amyloid precursor protein and beta-amyloid peptide by (-)-epigallocatechin-3-gallate in cell cultures: implications for iron chelation in Alzheimer's disease. J. Neurochem. 97, 527-536. doi: 10.1111/j.1471-4159.2006.03770.x

Rolfs, A., Kvietikova, I., Gassmann, M., and Wenger, R. H. (1997). Oxygenregulated transferrin expression is mediated by hypoxia-inducible factor-1. J. Biol. Chem. 272, 20055-20062. doi: 10.1074/jbc.272.32.20055

Roux, P. P., and Blenis, J. (2004). ERK and p38 MAPK-activated protein kinases: a family of protein kinases with diverse biological functions. Microbiol. Mol. Biol. Rev. 68, 320-344. doi: 10.1128/mmbr.68.2.320-344.2004

Ruscher, K., Freyer, D., Karsch, M., Isaev, N., Megow, D., Sawitzki, B., et al. (2002). Erythropoietin is a paracrine mediator of ischemic tolerance in the brain: evidence from an in vitro model. J. Neurosci. 22, 10291-10301.

Savage, M. J., Lin, Y. G., Ciallella, J. R., Flood, D. G., and Scott, R. W. (2002). Activation of c-Jun N-terminal kinase and p38 in an Alzheimer's disease model is associated with amyloid deposition. J. Neurosci. 22, 3376-3385.

Savory, J., Huang, Y., Wills, M. R., and Herman, M. M. (1998). Reversal by desferrioxamine of tau protein aggregates following two days of treatment in aluminum-induced neurofibrillary degeneration in rabbit: implications for clinical trials in Alzheimer's disease. Neurotoxicology 19, 209-214.

Schaeffer, H. J., and Weber, M. J. (1999). Mitogen-activated protein kinases: specific messages from ubiquitous messengers. Mol. Cell. Biol. 19, 2435-2444.

Schinder, A. F., and Poo, M. (2000). The neurotrophin hypothesis for synaptic plasticity. Trends Neurosci. 23, 639-645. doi: 10.1016/s0166-2236(00)01672-6
Schubert, D., and Chevion, M. (1995). The role of iron in beta amyloid toxicity. Biochem. Biophys. Res. Commun. 216, 702-707. doi: 10.1006/bbrc. 1995.2678

Schubert, D., Soucek, T., and Blouw, B. (2009). The induction of HIF-1 reduces astrocyte activation by amyloid beta peptide. Eur. J. Neurosci. 29, 1323-1334. doi: 10.1111/j.1460-9568.2009.06712.x

Semenza, G. L. (1998). Hypoxia-inducible factor 1, master regulator of O2 homeostasis. Curr. Opin. Genet. Dev. 8, 588-594. doi: 10.1016/s0959$437 \mathrm{x}(98) 80016-6$

Semenza, G. L. (1999). Regulation of mammalian O2 homeostasis by hypoxiainducible factor 1. Annu. Rev. Cell Dev. Biol. 15, 551-578. doi: 10.1146/annurev. cellbio.15.1.551

Siddiq, A., Ayoub, I. A., Chavez, J. C., Aminova, L., Shah, S., LaManna, J. C., et al. (2005). Hypoxia-inducible factor prolyl 4-hydroxylase inhibition. A target for neuroprotection in the central nervous system. J. Biol. Chem. 280, 41732-41743. doi: 10.1074/jbc.m504963200

Soucek, T., Cumming, R., Dargusch, R., Maher, P., and Schubert, D. (2003). The regulation of glucose metabolism by HIF-1 mediates a neuroprotective response to amyloid beta peptide. Neuron 39, 43-56. doi: 10.1016/s08966273(03)00367-2

Tacchini, L., Gammella, E., De Ponti, C., Recalcati, S., and Cairo, G. (2008). Role of HIF-1 and NF-kappaB transcription factors in the modulation of transferrin receptor by inflammatory and anti-inflammatory signals. J. Biol. Chem. 283, 20674-20686. doi: 10.1074/jbc.M800365200

Thoenen, H. (1995). Neurotrophins and neuronal plasticity. Science 270, 593-598. doi: $10.1126 /$ science. 270.5236 .593

Thoenen, H. (2000). Neurotrophins and activity-dependent plasticity. Prog. Brain Res. 128, 183-191. doi: 10.1016/s0079-6123(00)28016-3

Wang, G. L., Jiang, B. H., Rue, E. A., and Semenza, G. L. (1995). Hypoxia-inducible factor 1 is a basic-helix-loop-helix-PAS heterodimer regulated by cellular $\mathrm{O} 2$ tension. Proc. Natl. Acad. Sci. U S A 92, 5510-5514. doi: 10.1073/pnas.92. 12.5510

Weinreb, O., Amit, T., and Youdim, M. B. (2008). The application of proteomics for studying the neurorescue activity of the polyphenol (-)-epigallocatechin-3gallate. Arch. Biochem. Biophys. 476, 152-160. doi: 10.1016/j.abb.2008.01.004

Yue, P., Tao, T., Zhao, Y., Ren, J., and Chai, X. (2007). Huperzine A in rat plasma and CSF following intranasal administration. Int. J. Pharm. 337, 127-132. doi: 10.1016/j.ijpharm.2006.12.029

Zaman, K., Ryu, H., Hall, D., O’Donovan, K., Lin, K. I., Miller, M. P., et al. (1999). Protection from oxidative stress-induced apoptosis in cortical neuronal cultures by iron chelators is associated with enhanced DNA binding of hypoxiainducible factor-1 and ATF-1/CREB and increased expression of glycolytic enzymes, p21(waf1/cip1) and erythropoietin. J. Neurosci. 19, 9821-9830.

Zecca, L., Youdim, M. B., Riederer, P., Connor, J. R., and Crichton, R. R. (2004). Iron, brain ageing and neurodegenerative disorders. Nat. Rev. Neurosci. 5, 863-873. doi: $10.1038 / \mathrm{nrn} 1537$

Zelzer, E., Levy, Y., Kahana, C., Shilo, B. Z., Rubinstein, M., and Cohen, B. (1998). Insulin induces transcription of target genes through the hypoxia-inducible factor HIF-1alpha/ARNT. EMBO J. 17, 5085-5094. doi: 10.1093/emboj/17.17. 5085

Conflict of Interest Statement: The authors declare that the research was conducted in the absence of any commercial or financial relationships that could be construed as a potential conflict of interest.

Copyright $\odot 2015$ Guo, Zhang, Wang, Zhong, Yang, Hao, Chai and Zhang. This is an open-access article distributed under the terms of the Creative Commons Attribution License (CC BY). The use, distribution and reproduction in other forums is permitted, provided the original author(s) or licensor are credited and that the original publication in this journal is cited, in accordance with accepted academic practice. No use, distribution or reproduction is permitted which does not comply with these terms. 